\title{
Access to Maternal Health Services during COVID-19
}

\author{
Smriti Pant ${ }^{1 *}$, Saugat Koirala ${ }^{2}$, Madhusudan Subedi ${ }^{3}$
}

\author{
Author Info: \\ ${ }^{1}$ Lecturer, Department of \\ Community Health Sciences, \\ Patan Academy of Health \\ Sciences, Nepal
}

${ }^{2}$ Consultant, Department of Gynecology and Obstetrics, Dhaulagiri Hospital, Nepal

\section{${ }^{3}$ Professor and Chair, Department of Community Health Sciences, Patan Academy of Health Sciences, Nepal}

\section{*Corresponding Author:}

Dr. Smriti Pant

Email:

smritipant@pahs.edu.np drsmritipant@gmail.com Mobile No: 9841493898

\begin{abstract}
Most causes of maternal morbidity and mortality can be prevented by giving prompt, suitable treatment to the women by qualified health practitioners. Maternal health services (MHS), which include antenatal care, delivery care, and postnatal care, can play a crucial role in preventing maternal health problems. The recent coronavirus disease (COVID-19) pandemic has had a disastrous effect on the health care delivery system of people of all ages, on a global scale but pregnant women face particular challenges. The aim of this review is to assess the effect of COVID-19 on access to MHS. For writing this narrative review, national and international reports on maternal health services during COVID-19, along with journal articles on the related topic were reviewed. Due to this pandemic, women worldwide are facing more barriers to accessing maternal health care, including restrictions, transport challenges, and anxiety over possibly being exposed to coronavirus. Many women preferred not to seek healthcare due to the fear of themselves being infected with the virus or transmitting it to their unborn babies. Additionally, movement restriction has made it difficult for many pregnant women to reach health care facilities. Even those who managed to reach health facilities have reported not receiving timely care. As a result, a considerable rise in maternal mortality globally has been estimated over the next six months. Despite the circumstances, efforts have been made to boost maternal health in both developed and developing countries. This pandemic has highlighted the importance of health preparedness with special attention given to vulnerable people like pregnant women and newborns while planning for such events.
\end{abstract}

Keywords: Childbirth, COVID19, Maternal Health, Pandemic, Pregnancy, Women's health

Quick Response (QR) Code
Article Info




\section{BACKGROUND}

Pregnancy, childbirth and postnatal state is a very important period in a woman's life and her health during this phase is known as maternal health. ${ }^{1}$ Appropriate care is required during this period for prevention of maternal morbidity and mortality. Most causes of maternal morbidity and mortality can be prevented by giving prompt, suitable treatment to the women by qualified health practitioners. ${ }^{1} \quad$ Maternal health services(MHS), which include antenatal care, delivery care and postnatal care, ${ }^{2}$ can play a crucial role in preventing the maternal health problems. Considering its importance, maternal health and related issues are prioritized by many countries in their health agenda. As a result, in the past two and half decades, maternal mortality ratio has dropped by almost $38 \%$ globally. ${ }^{3}$ However, despite the global efforts there were 295,000 deaths in 2017 related to pregnancy and delivery. ${ }^{3}$ This may be the consequence of a decrease in utilization of MHS. The 'three delay' model is commonly used for identifying causes of such decrease. ${ }^{4}$ The delays include, delay in decision to seek health services, delay in reaching health care facility and delay in getting required care. ${ }^{4}$ The recent corona virus disease (COVID-19) pandemic has had a disastrous effect on the health care delivery system of people of all ages but pregnant women face particular challenges. ${ }^{5}$ The aim of this review is to assess the effect of COVID-19 on access to MHS. For writing this narrative review, national and international reports on maternal health services during COVID-19, along with journal articles on the related topic were reviewed.

\section{DELAYS IN MATERNAL HEALTH SERVICES}

Movement restrictions, transport challenges and anxiety over possibly being exposed to corona virus are acting as barriers to women who are trying to access maternal health care during the pandemic. ${ }^{6}$ United Nation's Population Fund ran a model to assess the probable effect of COVID-19 on sexual and reproductive health services including three indicators, namely births assisted by skilled health-care providers, institutional delivery and access to contraception. ${ }^{7}$ The analysis was focused on countries in Asia-Pacific region. ${ }^{7}$ The results showed that even in the best-case scenario the use of these services would decrease by one fifth of the present value while in the worst-case scenario the service utilization would decrease to half. ${ }^{7}$ This would subsequently lead to $17 \%$ and $43 \%$ rise in maternal mortality ratio respectively. ${ }^{7}$ In Nepal, a national survey in 2016 illustrated that only 58 percent of births in Nepal were attended by skilled health personnel, ${ }^{8}$ meaning many women faced serious risks if complication arose during child birth. The pandemic has further exacerbated the effect of the group of factors that lead to delays in availability and access of MHS. ${ }^{7}$

\section{Delay in decision to seek health care:}

Pregnant women are reported to have experienced increased anxiety as a result of COVID-19.9,10 A survey conducted in Italy among 100 pregnant women, to assess the psychological impact of the COVID-19, showed that more than half of the respondents rated themselves as having severe impact, and $68 \%$ stated that they had higher than normal anxiety. About $43 \%$ reported having anxiety concerning the possibility of transmission of the disease to their babies. ${ }^{9}$ In New York, many pregnant women expressed fear of visiting hospitals for childbirth because they were scared of being infected themselves or feared about vertical transmission. ${ }^{11}$ The dread and anxiety of visiting hospitals during COVID-19 has led many women to change their plan of childbirth and they are planning to have home deliveries. ${ }^{7,11,12}$ An increase in the number of home births has been reported in New York ${ }^{11}$ and different states of Australia. ${ }^{12}$ Similarly, in developing countries like Bangladesh ${ }^{7}$ and $\mathrm{Nepal}^{13}$ also more women are choosing to give birth at home. As deliveries in health facilities are related to reduction in risk for neonatal deaths ${ }^{14}$ when a woman hesitates to visit health facility for childbirth, it could lead to unfavorable outcomes for the newborn.

\section{Delay in reaching the health facility}

The lockdown and movement restriction, has caused difficulty for many pregnant women in reaching health care facilities. ${ }^{15,16}$ Pregnant women in Panama reported having problem in getting to health facility due to lack of transportation. ${ }^{15}$ In Zimbabwe, pregnant women faced problems in seeking care for their newborns due to movement restriction and distant pharmacies. ${ }^{16}$ Some states in India have recorded a drop in cases of institutional deliveries since the pandemic peaked. ${ }^{17}$ There have been reports of pregnant women delivering on the road and in ambulances, en route to the hospital, because of blockades amid the lockdown and delays of ambulanceservice. ${ }^{18-20}$ Similarly in Nepal, the number of women seeking antenatal and postnatal care has fallen significantly since the lockdown, along with the reduction in institutional 
deliveries. ${ }^{21}$ In Nepal, cases have been reported where, due to lack of transportation, women developed complications on the way to the hospital and died at the health facility before receiving proper care. ${ }^{22}$

\section{Delay in getting care:}

Even the women who managed to reach health facilities have reported not receiving timely care. In some facilities there was a shortage of health care workers, because many were engaged in treating COVID-19 patients while in other centers maternal health services were curtailed despite being classified as essential service. ${ }^{19}$ Additionally, a lack of preparedness of health institutions appears to be another factor that hinders service delivery in many countries. With rising number of COVID-19 patients and shortages of personal protective equipment, health workers are frightened, stressed and demoralized. ${ }^{23-25}$ In a survey among health workers involved in management of COVID-19 in Australia, majority of the respondents said that they were distressed by the lack of personal protective equipments(PPEs) in the hospitals. ${ }^{23}$ Another study done by The Edith Cowan University in Australia, among the medical workforce, showed that about $60 \%$ were less motivated than usual to work. ${ }^{23}$ About $70 \%$ of the participants said that they had to ration the use of PPE. ${ }^{23}$ They were scared that they would get infected (61\%) and were also concerned about the possibility to infect their family members(80\%). ${ }^{23}$ Similarly a research done among about 2500 physicians in Canada also illustrated that the respondents were very anxious and reported that this anxiety could be relieved by provision for adequate PPEs and testing. ${ }^{25}$ The lack of adequate PPEs for health workers seems to have affected the quality and quantity of health care.

Besides in many countries, health facilities don't have adequate infrastructure and equipment for management of COVID-19 patients. ${ }^{26-29}$ As a result many services regularly provided by the hospital, including MHS, have suffered. Even in developed countries like United States, some facilities have converted maternity wards to COVID-19 units, in order to accommodate the increasing number of COVID-19 patients. ${ }^{28}$ Hospitals also have a shortage of staff in neonatal intensive care units. ${ }^{28}$ To add to this, routine immunization services have also suffered during the pandemic which negatively impacts the well being of thennewborns. ${ }^{29}$ The situation is harsher in developing countries. Many countries in Africa have suffered tremendously due to lack of proper infrastructure and resources. ${ }^{26}$ In
India and Nepal also the pandemic has exposed shortfalls in the health system, with majority of health facilities being ill equipped to deal with the pandemic. ${ }^{26,28} 27$ Likewise, there is decreased availability of certain medications necessary for pregnant women, and decreased access to contraceptives for others. ${ }^{7,20}$

\section{CONSEQUENCES OF POOR MATERNAL HEALTH SERVICES}

Decreased access and utilization to MHS can have dire consequences for both women and newborns. Pregnant and postpartum women are already at high risk of nutritional deficiency during lockdown, due to decreased supply to nutritious food. On top of that, when they are unable to have regular antenatal and postnatal services, they will be deprived of the micronutrient supplements that they get from the clinics. In addition, without regular checkup there are chances of certain danger signs going unidentified, which makes them vulnerable to complications related to pregnancy and childbirth. Lancet published a report in May 2020, based on the use of the Lives Saved Tool (LiST), to estimate additional deaths as a result of decreased coverage of interventions, and increased prevalence of wasting. ${ }^{30}$ It reported that there could be considerable rise in maternal mortality at a global scale over the next six months due to the COVID-19 crisis. ${ }^{30}$ It also estimated that there was likelihood of rise in under-five mortality rate as well. ${ }^{30}$ In Nepal, the situation is already starting to look grim. According to Family Welfare Division of the Ministry of Health and Population, there have been at least 24 deaths due to birth-related complications since the lockdown was announced in March, 21, 2020.22

\section{EFFORTS TO ENHANCING MATERNAL HEALTH SERVICES}

Despite these circumstances, efforts have been made to boost maternal health in both developed and developing countries. Various IEC (Information, Education and Communication) materials have been produced to raise awareness regarding protection of mother and child during COVID-19.These include information disseminated by Royal College of Obstetrician and Gynecologists, ${ }^{31}$ American College of Obstetricians and Gynecologists, 32 World Health Organization, ${ }^{33}$ etc Due to the increasing number of home births, the state of New York decided to establish temporary birth centers, that would serve as a better alternative for low-risk pregnancies ${ }^{11}$ Similarly, help hotlines have been established by various health facilities. ${ }^{34-37}$ National 
Health Foundation in UK, launched Pregnancy and postnatal helpline which is answered by midwives. ${ }^{36}$ In India, some states have established pregnancy hotline to provide advice to women in need. ${ }^{37}$ Other states have started phone-in services to help with transportation to pregnant women. ${ }^{38}$ Additionally, virtual consultation with obstetricians have been provided via telemedicine services, to women seeking MHS. ${ }^{39}$ Even in Nepal, a hotline service is being run by Midwives' Society of Nepal to provide both clinical and psychological guidance to would be and postnatal mothers. ${ }^{34}$ Some volunteers from Bibeksheel Nepali Party have been providing aid in getting ration or transportation to the needy. ${ }^{35}$

\section{CONCLUSIONS \& RECOMMENDATIONS}

The COVID-19 pandemic is an unprecedented event that took the world by surprise. It has caused disruption of health services on the global scale, including MHS. Various modalities used to combat the infection have exacerbated the delays in access to MHS including the delays in decision to seek health services, reaching health facilities and getting required care. Overwhelmed health centers, lack of resources and movement restrictions have had a negative impact on the utilization of MHS. Despite the efforts made to curtail the effect, estimates suggest that the maternal and child, morbidity and mortality will rise in the months to come. What the COVID-19 pandemic has taught us is that health preparedness is necessary for dealing with any unprecedented situation in the future. Special attention should be given to vulnerable people like pregnant women and newborns while planning for such events. Effective preventive and clinical strategies are needed to control COVID-19 infection among pregnant women and lactating mothers. Governments also need to make sure that women can access basic information to protect the health of themselves and their babies. Arrangements should be made for assuring proper means of transportation and availability of MHS during lockdown.

\section{Authors' contributions:}

SP conceptualized the idea for review.

SP and SK were major contributors in writing the manuscript.

MS gave inputs for the improvement of the article. All authors reviewed and approved the final manuscript.

\section{REFERENCES}

1. World Health Organization. Maternal health. World Health Organization. 2018 [cited 2020 Jun 20]. [Link]

2. World Health Organization. World Health Day 1998 : Improve the Quality of Maternal Health Services. World Health Organization; 1998 [cited 2020 Jun 21]. [Link]

3. World Health Organization. Maternal mortality. World Health Organization. 2019. [cited 2020 Jun 21]. [Link]

4. Calvello EJ, Skog AP, Tenner AG, Wallis LA. Applying the lessons of maternal mortality reduction to global emergency health. WHO Bulletin. 2015;93:417-23. https://doi.org/10.2471/BLT.14.146571 [PubMed]

5. Cohut M. The effect of the COVID-19 pandemic on primary healthcare worldwide. Medical News Today. 2020 [cited 2020 Jun 21]. [Link]

6. United Nations Children Fund. Maternal and newborn health and COVID-19. UNICEF DATA. 2020 [cited 2020 Jun 21]. [Link]

7. Beni DDe, Maurizio F. Coronavirus is leaving pregnant women with tough choices and bleaker outcomes. World Economic Forum. 2020 [cited 2020 Jun 22]. [Link]

8. Ministry of Health, Nepal,New ERA,CF. Nepal Demographic Health Survey 2016. Kathmandu,Nepal: Ministry of Health, Nepal.; 2017. [cited 2020 Jun 20] [Link]

9. Saccone $G$, Florio $A$, Aiello $F$, Venturella $R, D e$ Angelis MC, Locci $M$, et al. Psychological impact of coronavirus disease 2019 in pregnant women. Am. J. Obstet. Gynecol.2020;S0002937820305275. https:// doi.org/10.1016/j.ajog.2020.05.003 [PubMed]

10. Durankuş F, Aksu E. Effects of the COVID-19 pandemic on anxiety and depressive symptoms in pregnant women: a preliminary study. 1. Matern.Fetal Neonatal Med. 2020;0(0):1-7. https://doi.org/ $10.1080 / 14767058.2020 .1763946$ [EPUB]

11. Kimiko de Freytas-Tamura. Pregnant and Scared of 'Covid Hospitals,' They're Giving Birth at Home. The New York Times. 2020 [cited 2020 Jun 22] [Link]

12. Bradfield A. Calls for urgent Medicare rebates as women choose homebirth over hospital.ABC News 2020 [cited 2020 Jul 6]. [Link]

13. Chhetri S. In Nepal, COVID-19 turning pregnancy excitement into fear. United Nations Population Fund. 2020 [cited 2020 Jun 21]. [Link]

14. Tura G, Fantahun M, Worku A. The effect of health facility delivery on neonatal mortality: systematic review and meta-analysis. BMC Pregnancy Childbirth. 2013;13(1):18. https://doi.org/10.1186/1471-239313-18 [Google Scholar] 
15. Arrocha V. Pregnant indigenous women in Panama face COVID-19 fears, lack of transport. United Nations Population Fund. 2020 [cited 2020 Jun 22]. [Link]

16. Chikwanda V. The devastating effects of COVID-19 on maternal health in Zimbabwe. Amnesty International. 2020 [cited 2020 Jun 22]. [Link]

17. Ghose D, Angad A. Institutional deliveries dip in Chhattisgarh, Jharkhand. The Indian Express. 2020 [cited 2020 Jun 24]. [Link]

18. Indo Asian News Service. COVID-19 lockdown: Unable to reach hospital, Telangana woman delivers baby on road. The New Indian Express. 2020[cited 2020 Jun 22]. [Link]

19. Bisht R, Sarma J. COVID-19 Lockdown: Guidelines Are Not Enough to Ensure Pregnant Women Receive Care. The Wire. 2020[cited 2020 Jun 22]. [Link]

20. Jaswal M. Coronavirus: Pregnant women struggle to access healthcare facilities amid lockdown. Business Today. 2020 [cited 2020 Jun 22]. [Link]

21. Poudel A. Fewer women are visiting health facilities for maternal services during lockdown. The Kathmandu Post. 2020 [cited 2020 Jun 21]. [Link]

22. Poudel A. A 200 percent increase in maternal mortality since the lockdown began. The Kathmandu Post. 2020[cited 2020 Jun 22]. [Link]

23. Woodley M. Dire PPE shortage affecting morale: Study. Royal Australian College of General Practitioners. 2020 [cited 2020 Jun 22]. [Link]

24. Wiley B, Timms P, Scott S. "Guilt and shame" for wearing masks as doctors report widespread sharing. ABC News. 2020 [cited 2020 Jun 22]. [Link]

25. Canadian Medical Association .Continued lack of PPE, testing high sources of anxiety for physicians, new CMA poll says. Canadian Medical Association.2020 [cited 2020 Jun 24]. [Link]

26. Human Rights Watch. Africa: Covid-19 Exposes Healthcare Shortfalls. Human Rights Watch. 2020 [cited 2020 Jun 22]. [Link]

27. Mohanty P. Coronavirus Lockdown III: Is India's public healthcare system prepared to fight the COVID-19 menace? Business Today. 2020 Apr 3 [cited 2020 Jun 22]. [Link]
28. Stein D, Ward K, Cantelmo C. Estimating the Potential Impact of COVID-19 on Mothers and Newborns in Low- and Middle-Income Countries. Health Policy Plus. 2020 [cited 2020 Jun 21]. [Link]

29. Dhakal S. Hospitals ill-equipped to handle COVID-19 patients. The Himalayan Times. 2020[cited 2020 Jun 22]. [Link]

30. Roberton T, Carter ED, Chou VB, Stegmuller AR, Jackson BD, Tam Y, et al. Early estimates of the indirect effects of the COVID-19 pandemic on maternal and child mortality in low-income and middle-income countries: a modelling study. Lancet Glob Health. 2020 (7):e901-8. https://doi.org/10.1016/S2214109X(20)30229-1 [PMC

31. Royal College of Obstetricians \& Gynaecologists. Coronavirus infection and pregnancy .2020 [cited 2020 Jul 8]. [Link]

32. American College of Obstetricians \& Gynaecologists. Coronavirus (COVID-19), Pregnancy, and Breastfeeding. 2020[cited 2020 Jul 8]. [Link]

33. World Health organization. Pregnancy, Childbirth, breastfeeding and COVID-19. World Health organization.2020[cited 2020 Jul 8]. [Link]

34. Shrestha $E$, Heaton T. Like most vulnerable groups, soon-to-be and new mothers face an uncertain near future. The Kathmandu Post. 2020 [cited 2020 Jun 23]. [Link]

35. Hyolmo K. COVID-19: Bibekseel Nepali Dal sets up hotline for public. My Republica.2020 [cited 2020 Jun 23]. [Link]

36. National Health Service. Pregnancy and postnatal helpline launched .Bolton NHS FT . National Health Service Bolton. 2020 [cited 2020 Jun 23]. [Link]

37. Mukesh A. City admin launches maternity helpline no. to help pregnant women. The Times of India. 2020 [cited 2020 Jun 23]. [Link]

38. United Nations Population Fund Asiapacific. In India's Bihar state, lifesaving support for pregnant women and new mothers amid COVID-19. UNFPA Asiapacific. 2020 [cited 2020 Jun 24]. [Link]

39. Mukherjee K. Telemedicine: Health in the time of pandemic. The New Indian Express. 2020 [cited 2020 Jun 23]. [Link] 